\title{
Vitamin E, Vitamin C, or Losartan Is Not Nephroprotectant against Cisplatin-Induced Nephrotoxicity in Presence of Estrogen in Ovariectomized Rat Model
}

\author{
Mehdi Nematbakhsh, ${ }^{1,2,3}$ Zahra Pezeshki, ${ }^{1}$ Fatemeh Eshraghi-Jazi, ${ }^{1}$ \\ Farzaneh Ashrafi, ${ }^{1,4}$ Hamid Nasri, ${ }^{1,3}$ Ardeshir Talebi, ${ }^{1,5}$ Tahereh Safari, ${ }^{1,2}$ \\ Maryam Haghighi, ${ }^{1}$ and Azam Mansouri ${ }^{1}$ \\ ${ }^{1}$ Water and Electrolytes Research Center, Isfahan University of Medical Sciences, HezarJerib Avenue, Isfahan 81745, Iran \\ ${ }^{2}$ Department of Physiology, Isfahan University of Medical Sciences, HezarJerib Avenue, Isfahan 81745, Iran \\ ${ }^{3}$ Kidney Diseases Research Center, Isfahan University of Medical Sciences, HezarJerib Avenue, Isfahan 81745, Iran \\ ${ }^{4}$ Department of Internal Medicine, Isfahan University of Medical Sciences, HezarJerib Avenue, Isfahan 81745, Iran \\ ${ }^{5}$ Department of Clinical Pathology, Isfahan University of Medical Sciences, HezarJerib Avenue, Isfahan 81745, Iran
}

Correspondence should be addressed to Mehdi Nematbakhsh, nematbakhsh@med.mui.ac.ir

Received 12 June 2012; Revised 14 August 2012; Accepted 20 August 2012

Academic Editor: James E. Springate

Copyright (C) 2012 Mehdi Nematbakhsh et al. This is an open access article distributed under the Creative Commons Attribution License, which permits unrestricted use, distribution, and reproduction in any medium, provided the original work is properly cited.

\begin{abstract}
Background. The nephroprotective effect of vitamins $\mathrm{E}$ and $\mathrm{C}$ or losartan against cisplatin (CP)- induced nephrotoxicity when they are accompanied by estrogen was investigated. Methods. The ovariectomized rats received estradiol valerate for two weeks. At the end of the first week, a single dose of CP ( $7 \mathrm{mg} / \mathrm{kg}$, IP) was also administered, and they received placebo (group 1), vitamin E (group 2), vitamin C (group 3), or losartan (group 4) every day during the second week, and they were compared with another three control groups. Results. CP alone increased the serum levels of blood urea nitrogen (BUN), creatinine (Cr), and kidney tissue damage score (KTDS), significantly $(P<0.05)$, however at the presence of estradiol and $\mathrm{CP}$, vitamin $\mathrm{C}$, vitamin $\mathrm{E}$, or losartan not only did not decrease these parameters, but also increased them significantly $(P<0.05)$. The serum level of superoxidase dismutase (SOD) was reduced by CP $(P<0.05)$, but it was increased when estradiol or estradiol plus vitamin $\mathrm{C}$ or losartan were added $(P<0.05)$. Conclusion. The particular pharmacological dose of estrogen used in this study abolish the nephroprotective effects vitamins $\mathrm{C}$ and E or losartan against CP-induced nephrotoxicity.
\end{abstract}

\section{Introduction}

Nephrotoxicity is the major adverse effect of cisplatin (CP) in about 30 percent of patients during chemotherapy in clinic due to tubular toxicity, inflammation, oxidative stress, and change in the renal circulation [1-4], and it is a limitation for CP use. To avoid this side effect and based on different experimental designs, protective role of administration of many synthetic or herbal agents as supplementation has been investigated against CP-induced nephrotoxicity [5-34], including vitamins $\mathrm{E}$ and $\mathrm{C}$ and losartan as antioxidant agents $[5,6,22,23]$. During $C P$ chemotherapy, plasma antioxidant concentrations decrease, and in human subject coadministrations of vitamin $\mathrm{C}$, vitamin $\mathrm{E}$, and selenium markedly increase plasma antioxidant levels [35]. In addition, the protective role of vitamin $\mathrm{E}$ supplementation against CP-induced peripheral neuropathy in patients was evaluated, and its neuroprotective role was reported [36, 37]. Although vitamins $\mathrm{C}$ and $\mathrm{E}$ and losartan have antioxidant effects $[22,23,38,39]$, losartan itself acts as a blocker of angiotensin II receptor 1 (ATR1), which facilitates renal circulation $[40,41]$. The protective effect of losartan against CP-induced nephrotoxicity was reported before $[5,6]$, and it has no effect on CP uptake by the kidney [6]. However, acute administration of losartan does not affect the CP-induced kidney toxicity [5]. 
The protective role of estrogen in cardiovascular system in women before menopause is well documented [42-47]. The incidence of chronic renal diseases is also gender related and is potentially higher in males $[48,49]$, which may relate to estrogen-mediated vascular endothelial growth factor [48]. It is reported that estrogen receptors may be disturbed by $\mathrm{CP}$, the steroid hormone increases the potency of $\mathrm{CP}[50]$, and estrogen may enhance oxidative stress in the kidney [51]. Therefore, not only the protective role of estrogen against CP-induced nephrotoxicity may be failed, but also its adverse side effect in CP-induced kidney toxicity became a question. Recently, we have compared the CP-induced kidney damage in male and female rats, and demonstrated that the CPinduced nephrotoxicity is gender related [52]. The protective role of losartan against CP-induced nephrotoxicity also indicates that losartan as an antioxidant is nephroprotectant in males but not in females [53]. So, one question is raised about the role of female sex hormone in this gender-based difference. Accordingly, we hypothesized that administration of estrogen and $\mathrm{CP}$ together promotes the potency of CPinduced nephrotoxicity, which abolishes the nephroprotective effects of antioxidants such as vitamins $\mathrm{C}$ and $\mathrm{E}$ and losartan. To test this hypothesis and in the first step, the effect of estrogen and its combination with vitamin E, vitamin C, or losartan in CP-induced nephrotoxicity should be determined. Therefore, ovariectomized rats were treated with the pharmacological dose of estradiol valerate. Then, particular doses of vitamin C, vitamin E, or losartan plus single dose of $\mathrm{CP}$ were administered, and the results were compared with those obtained from the control groups.

\section{Materials and Methods}

2.1. Animals. Forty-two adult female Wistar rats (Animal Centre, Ahvaz University of Medical Sciences, Ahvaz, Iran) with the mean weight of $182 \pm 2.7 \mathrm{~g}$ were used. The rats were individually housed at a temperature of $23-25^{\circ} \mathrm{C}$. Rats had free access to water and chow. The experimental procedures were in advance approved by the Isfahan University of Medical Sciences Ethics Committee.

2.2. Drugs. CP (cis-diammineplatinum (II) dichloride, code P4394), vitamin E, and vitamin C were purchased from Sigma (St. Louis, MO, USA). Estradiol valerate was obtained from Aburaihan Co. (Tehran, Iran). Losartan was provided by Darupakhsh Pharmaceutical Company (Tehran, Iran).

2.3. Experimental Protocol. The animals were anesthetized by injection of $75 \mathrm{mg} / \mathrm{kg}$, IP ketamine. An incision was made in the subabdominal region. The abdominal muscles were opened. The uterus tube and vascular base of ovaries were twisted, and the ovaries were removed. The muscles and skin were stitched backed into the place. After recovery, the animals were allowed to acclimatize to the same diet at least for one week. Then, they were randomly divided into seven experimental groups as follows.

Group 1: $2.5 \mathrm{mg} / \mathrm{kg} /$ week estradiol valerate in sesame oil was injected intramuscular for two weeks, and at the end
TABLE 1: Summary of the treatment in the groups. Estradiol was injected at the beginning of each week. CP was administrated as a single dose at the beginning of the second week. The vitamins and losartan were injected daily during the second week.

\begin{tabular}{lcc}
\hline Group & First week & Second week \\
\hline 1 & Estradiol & Estradiol + CP + saline \\
2 & Estradiol & Estradiol + CP + vitamin E \\
3 & Estradiol & Estradiol + CP + vitamin C \\
4 & Estradiol & Estradiol + CP + losartan \\
5 & Saline & CP \\
6 & Estradiol & Estradiol \\
7 & Saline & Saline \\
\hline
\end{tabular}

of the first week, blood sample was obtained and a single dose of CP $(7 \mathrm{mg} / \mathrm{kg}$, IP) was also administered. Then, the animals received $0.5 \mathrm{~mL} / \mathrm{rat} /$ day vehicle (saline) during the second week.

Groups 2 to 4: the groups had regimen the same as group 1 , except that vitamin E $(1 \mathrm{~g} / \mathrm{kg} /$ day, group 2$)$, vitamin C $(250 \mathrm{mg} / \mathrm{kg} /$ day, group 3), or losartan $(10 \mathrm{mg} / \mathrm{kg} /$ day, group 4) was administered instead of vehicle during the second week. Blood samples were also obtained at the end of the first week.

Group 5 (positive control) received saline for two weeks, and at the end of the first week, blood sample was obtained. At the end of the first week, a single dose of CP alone was administered. Similarly, group 6 was treated by estradiol alone $(2.5 \mathrm{mg} / \mathrm{kg} /$ week estradiol valerate for two weeks $)$, and group 7 (negative control) received vehicle alone during the experiment.

At the end of the experiment (one week after CP injection), blood samples were obtained again and the rats were sacrificed by anaesthesia drug overdose. Kidneys and uterus were removed and weighted immediately, and the left kidney was prepared for histopathological procedures. Summary of the experimental protocol for each group of experiment is provided in Table 1.

2.4. Measurements. Body weight of the animals was recorded daily. The levels of serum creatinine ( $\mathrm{Cr}$ ), blood urea nitrogen $(\mathrm{BUN})$, and magnesium $(\mathrm{Mg})$ were determined using quantitative diagnostic kits (Pars Azmoon, Tehran, Iran). Serum level of nitrite (stable NO metabolite) was measured using a colorimetric ELISA kit (Promega Corporation, USA) that involves the Griess reaction. Serum level of estradiol was measured using enzyme immunoassay ELISA kit (Diagnostics Biochem Canada Inc., Canada). The serum level of superoxidase dismutase (SOD) was determined by a doubleantibody sandwich enzyme-linked immunosorbent assay ELISA kits (Glory Science Co., USA). For each of the abovementioned parameters, the concentration difference $(\Delta)$ was defined and calculated as (end of the second week (one week after CP administration) concentration - end of the first week (before $\mathrm{CP}$ administration) concentration).

2.5. Histopathological Procedures. The removed kidneys were fixed in $10 \%$ neutral formalin solution and embedded in 
TABLE 2: The mortality rate of animals in each group during the second week of the experiment.

\begin{tabular}{|c|c|c|c|c|c|c|c|c|c|}
\hline \multirow{2}{*}{ Group } & \multirow{2}{*}{$N$} & \multicolumn{7}{|c|}{ Day } & \multirow{2}{*}{$n$} \\
\hline & & 1 & 2 & 3 & 4 & 5 & 6 & 7 & \\
\hline Number 1: estradiol + CP & 6 & - & - & - & - & - & - & - & 6 \\
\hline Number 2: estradiol $+\mathrm{CP}+$ vitamin $\mathrm{E}$ & 7 & - & - & - & - & - & - & - & 7 \\
\hline Number 3: estradiol + CP + vitamin C & 7 & - & - & - & - & 1 & 2 & 1 & 3 \\
\hline Number 4: estradiol + CP + losartan & 7 & - & - & - & - & 1 & 1 & 2 & 3 \\
\hline Number 5: CP + vehicle (positive control) & 5 & - & - & - & - & - & - & - & 5 \\
\hline Number 6: estradiol + vehicle (negative control) & 5 & - & - & - & - & - & - & - & 5 \\
\hline Number 7: vehicle (negative control) & 5 & - & - & - & - & - & - & - & 5 \\
\hline
\end{tabular}

$N$ : total number of animals at the beginning of experiment. All animals were ovariectomized, $n$ : number of animals at the end of the experiment, CP: cisplatin. $\mathrm{CP}$ was administered at the beginning of the second week.

paraffin for hematoxylin and eosin staining to examine the tubular damage. The damage was evaluated by two independent pathologists who were totally blind to the study. Based on the intensity of tubular lesions (hyaline cast, debris, vacuolization, flattening and degeneration of tubular cells, and dilatation of tubular lumen), kidney tissue damage score (KTDS) was graded from 1 to 4 , while score zero was assigned to normal tubules without any damage.

2.6. Statistical Analysis. Data are expressed as mean \pm SEM. The percentage of changes in the body weight, the difference (after-before, $\Delta$ ) of BUN, Cr, Mg, SOD, estradiol, and nitrite serum levels, and the kidney and the uterus weights in groups $1-4,6$, and 7 were compared with group 5 (the positive control group) using Student's $t$-test. The same comparison was applied to the KTDS using Mann-Whitney analysis. The $P$ values $\leq 0.05$ were considered statistically significant.

\section{Results}

The number of animals in each group and animals survived in the seven experiment groups are shown in Table 2. The mortality rate was more than 50 percent in groups 3 and 4 (Table 1). No mortality rate was observed in others groups.

\subsection{Effect of CP: Comparison between Positive (Group 5) and} Negative Control (Group 6 and 7) Groups. The serum difference levels (one week after $\mathrm{CP}$ administration-before $\mathrm{CP}$ administration; $\Delta$ ) of BUN, $\mathrm{Cr}, \mathrm{Mg}, \mathrm{SOD}$, estradiol, and nitrite; the kidney and the uterus weights; the KTDS in vehicle alone, estradiol alone, or CP alone (the positive control group) treated ovariectomized groups are demonstrated in Figure 1.

The serum levels of BUN and Cr, and KTDS significantly increased in the positive control group $(P<0.05)$ when compared with negative control groups (groups 6 and 7). This finding confirms kidney toxicity induced by CP. No significant differences were observed in the serum $\mathrm{Mg}$ levels between positive and negative control groups; indicating that no $\mathrm{Mg}$ depletion occurred by CP during one-week treatment with CP. Administration of CP reduced the serum levels of nitrite and SOD, while increase of these parameters was observed in the negative control groups $(P<0.05)$.
The serum level of estradiol and uterus weigh in group 6 increased significantly $(P<0.05)$ when compared with groups 5 and 7; indicating that estradiol administration increases the blood estrogen level.

\subsection{Effect of Vitamin C, Vitamin E, or Losartan: Comparison} between Positive Control (Group 5) and Case Groups (Groups 1, 2, 3, and 4). The serum difference levels (one week after $\mathrm{CP}$ administration-before $\mathrm{CP}$ administration; $\Delta$ ) of BUN, $\mathrm{Cr}$, $\mathrm{Mg}$, SOD, estradiol, and nitrite; the kidney and the uterus weights; KTDS in estradiol and CP (group 1), estradiol plus vitamin $\mathrm{E}$ and $\mathrm{CP}$ (group 2), estradiol plus vitamin $\mathrm{C}$ and $\mathrm{CP}$ (group 3), estradiol plus losartan and CP (group 4) treated ovariectomized groups in comparison with ovariectomized rats treated with CP alone (the positive control group; group 5 ) are demonstrated in Figure 2. At the presence of estradiol, vitamin $\mathrm{C}$, vitamin $\mathrm{E}$, or losartan not only did not decrease the serum levels of BUN and $\mathrm{Cr}$, and kidney weight or KTDS in ovariectomized rats, but also significantly increased these parameters when compared with the positive control group $(P<0.05)$. No significant differences were observed in $\Delta$ nitrite, $\Delta \mathrm{Mg}$, and percentage change of weight between groups 1 to 5 . The serum level of SOD in CP-treated rats was significantly increased by estradiol, estradiol plus vitamin C, and estradiol plus losartan $(P<0.05)$. Such finding was not observed for estradiol plus vitamin $\mathrm{E}$.

According to these findings, the vitamins or losartan has no beneficial effects against CP-induced nephrotoxicity when estradiol is present. Samples of kidney tissue images from each experimental group are shown in Figure 3.

\section{Discussion}

Our findings indicate that coadministration of vitamin C, vitamin $\mathrm{E}$, or losartan with estradiol in female rats has no protective effect on the onset or severity of nephrotoxicity induced by $\mathrm{CP}$, although previous reports indicated nephroprotectant effects for vitamins and ATR1 blocker, losartan, against CP-induced nephrotoxicity $[5,6,22,23]$. The incidence rates of both cardiovascular and renal diseases are gender related and are higher in males. In the cardiovascular system, protective role of estrogen before menopause is well known [44-46]. However, estrogen may enhance oxidative 

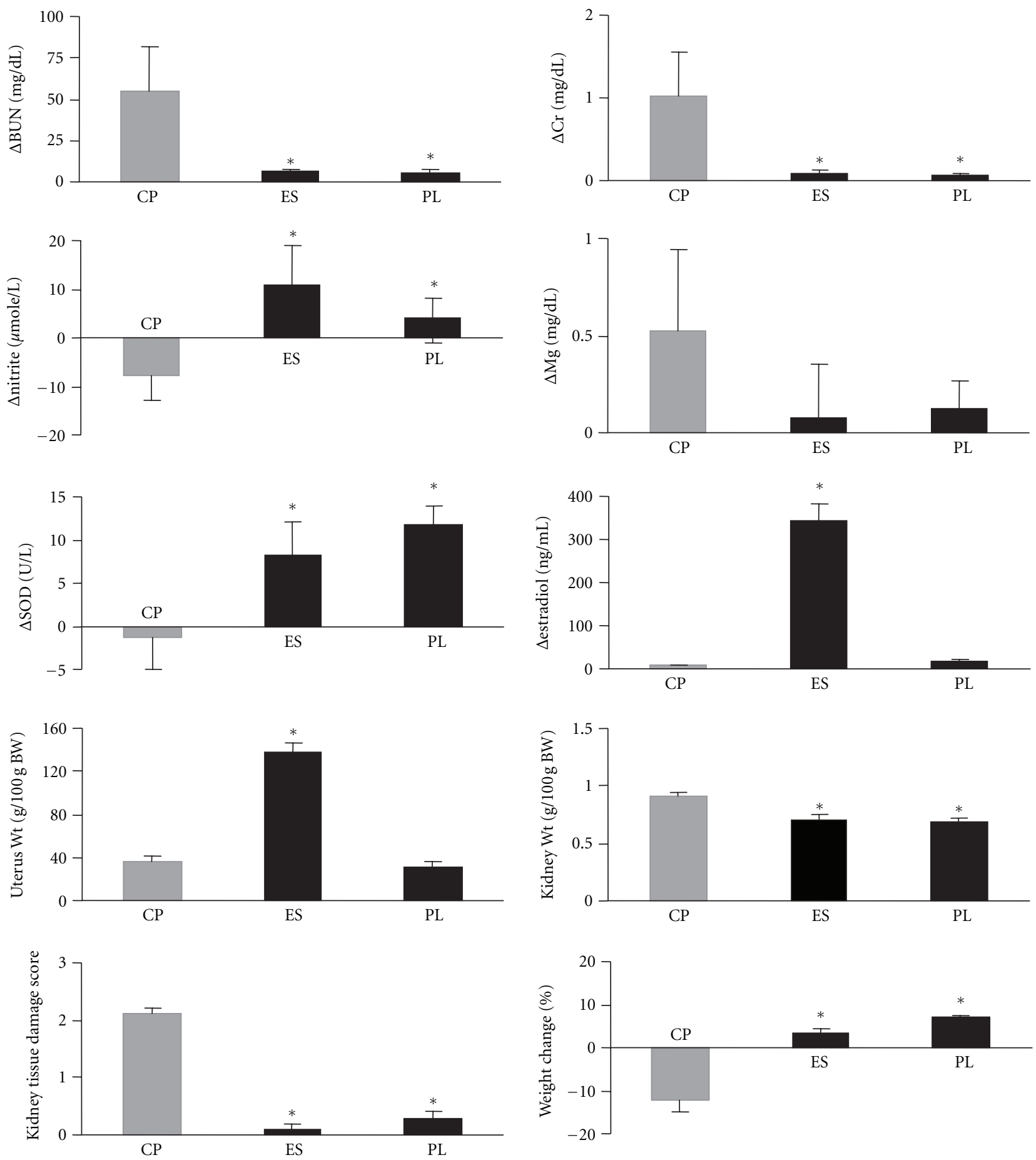

Figure 1: The serum difference levels (one week after CP administration - before CP administration; $\Delta$ ) of BUN, Cr, Mg, SOD, estradiol, and nitrite; the kidney and the uterus weights; the KTDS in vehicle, estradiol, or CP (the positive control group) alone-treated ovariectomized groups. The star indicates significant difference $(P<0.05)$ when compared with the positive control groups. CP, ES, and PL on the horizontal axes stand for groups treated with CP (group 5), estradiol valerate (group 6), and vehicle (placebo, group 7), respectively.

stress in the kidney [51], and the oxidative stress induced by estrogen will enhance CP-induced injury to the tubules. In this study, we demonstrated for the first time that estrogen did not reduce the severity of nephrotoxicity, and actually it abolished the regular protective effect of antioxidants such as vitamin $\mathrm{C}$, vitamin $\mathrm{E}$, and losartan against $\mathrm{CP}$-induced nephrotoxicity [34, 54-56], despite that estrogen itself has an antioxidant effect too. Instead of physiological dose of estrogen, we used the pharmacological dose of estradiol to establish the effect of estradiol first, and the result of this 

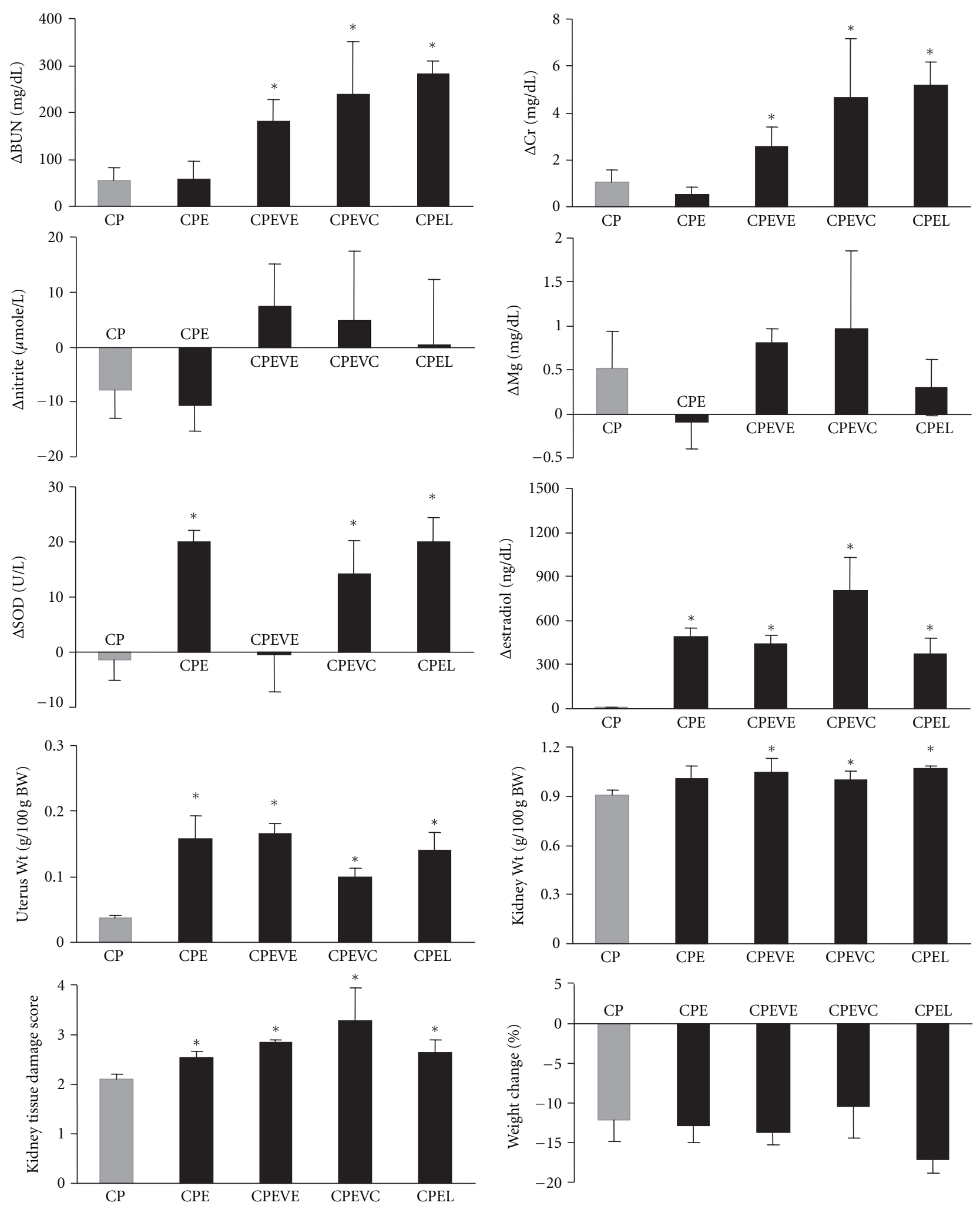

FIgure 2: Serum difference levels (one week after CP administration - before CP administration; $\Delta$ ) of BUN, Cr, Mg, SOD, estradiol, and nitrite; the kidney and the uterus weights; and KTDS in estradiol and CP, estradiol plus vitamin E and CP, estradiol plus vitamin C and $\mathrm{CP}$, estradiol plus losartan and CP-treated ovariectomized groups (group 1-4) compared with ovariectomized rats treated with CP alone (positive control group). CP, CPE, CPEVE, CPEVC, and CPEL on the horizontal axes stand for groups treated with CP alone (group 5), estradiol and CP (group1), estradiol plus vitamin E and CP (group 2), estradiol plus vitamin C and CP (group 3), and estradiol plus losartan and CP (group 4), respectively. The star indicates significant difference $(P<0.05)$ when compared with the positive control group. 

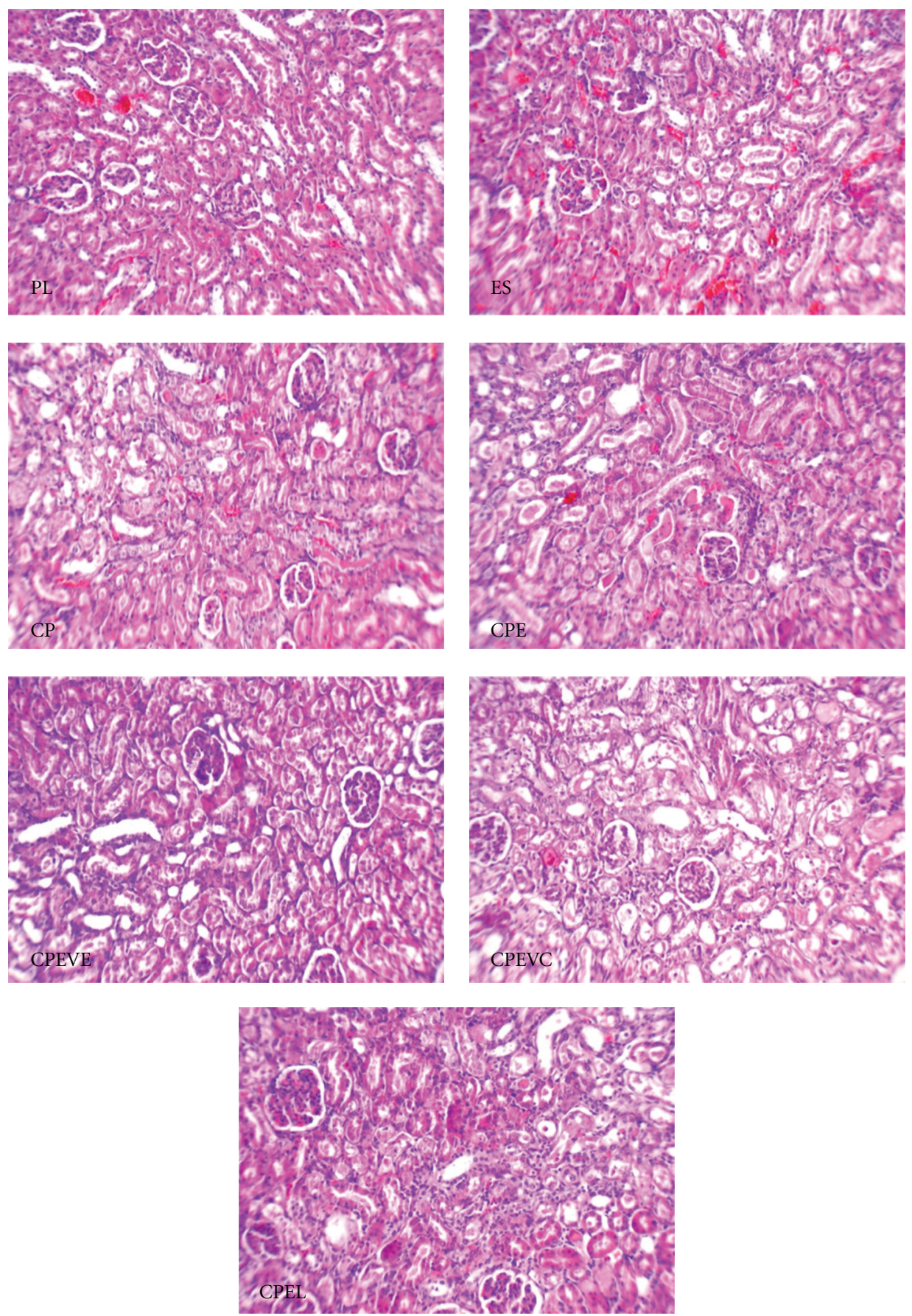

FIGURE 3: Images (magnification $\times 100$ ) of kidney tissue. PL, ES, CP, CPE, CPEVE, CPEVC, and CPEL inside the images stand for groups treated with vehicle (placebo, group 7), estradiol valerate (group 6), CP alone (group 5), estradiol and CP (group 1), estradiol plus vitamin E and CP (group 2), estradiol plus vitamin C and CP (group 3), and estradiol plus losartan and CP (group 4), respectively. No tissue damages were seen in PL and ES, but higher and almost similar tissue damages were observed in other groups.

study strongly suggests examining the dose response of estradiol for future studies.

4.1. CP, BUN, Cr, Kidney Weight, Body Weight, Estrogen, and KTDS. According to the serum levels of BUN and $\mathrm{Cr}$, and pathology damage score, nephrotoxicity was verified in all
CP-treated animals (Figure 2). CP also caused weight reduction similar to our previous study [34]. The uterus weight increased in all estradiol-treated groups due to the presence of estradiol. The kidney tissue weight increases in CPinduced nephrotoxicity [57], and our findings were similar in this study. The KTDS in CP plus estradiol-treated groups either with or without vitamins or losartan was significantly 
greater than that in CP alone treated group. This data reveals the more significant role of coadministration of estrogen that abolishes the protective effect of vitamins or losartan against CP-induced nephrotoxicity. There are two possible explanations for the observation. Estrogen and CP may have two different effects on endothelial nitric oxide (NO). The first increases NO, and the second decreases the level [58-62]. These two opposite effects may restore the serum level of NO. However, estrogen-induced NO may enhance the severity of nephrotoxicity [62]. The second explanation is related to formation of oxidative stress induced by ovariectomy [63] and by CP administration [3]. These oxidative stresses play an effective role to promote the kidney injury.

4.2. CP, Estrogen, and NO. CP alone causes dose-dependent declines in glomerular filtration rate (GFR) and renal blood flow due to renal vascular resistance changes $[1,4]$. This phenomenon may limit CP transport to the kidney circulation. On the other hand, estrogen promotes formation of vasodilator biomarkers such as NO $[58,60,61]$. Our findings are in agreement with this item, as the serum level of $\mathrm{NO}$ metabolite (nitrite) elevated in the estrogen alone-treated group (Figure 1). NO involves in the process of CP-induced nephrotoxicity [64], and CP increases the level of inducible NO synthase [65] and decreases the level of endothelial NO synthase [59]. In addition, enhancement of NO level could increase the severity of toxicity [62]. It is also reported that inhibition of NO synthase aggravates CP-induced nephrotoxicity [57, 66]. Therefore, coadministration of CP and estrogen may promote the severity of toxicity due to estrogen-induced NO production. Another factor to consider is the availability of estrogen receptors in kidneys. Estradiol possibly sensitizes tubular cells to $\mathrm{CP}$, similar to what happens in breast cancer cells [50], and promotes the tissue toxicity.

4.3. CP, Estrogen, and Oxidative Stress. It is well documented that abnormal production of reactive oxygen molecules, called oxidative stress, is involved in CP-induced nephrotoxicity, and CP produces renal oxidative stress, which disturbs renal function due to its toxicity [67]. Vitamins $\mathrm{C}$ and $\mathrm{E}$ reduce the level of SOD in CP-induced nephrotoxicity model [68]. Losartan also has antioxidant effect, and it may improve the renal function and decrease the severity of CP-induced nephrotoxicity $[5,6]$. Estrogen also has antioxidant effect [54-56], and similar to vitamin E can modulate oxidativestress-induced kidney toxicity $[69,70]$. This is while other research indicated that estrogen enhances the oxidative stress in kidney [51]. In our study, the serum level of SOD was decreased by CP (Figure 1), and it was increased when estrogen alone or in combination of estrogen and vitamin $\mathrm{C}$ or losartan was administered. Opposite to these findings, Ulas and Cay [69] studied diabetic rat model, and no increment of SOD was detected in estradiol plus vitamin E treated rats. The level of serum SOD in ovariectomized rats treated either by estradiol or combination of estradiol and vitamin E was reported to be higher than nontreated ovariectomized animals [71], and this supplementation reduces lipid peroxidation [69]. But on the other hand, CP reduced the SOD level as an antioxidant defense system [72]. Considering our results, it seems that $\mathrm{CP}$ abolishes the antioxidant defense system induced by vitamin $\mathrm{E}$ and possibly estradiol due to possible pharmacokinetic or pharmacodynamic drug interactions.

4.4. CP, Estrogen, and $\mathrm{Mg}$. The serum levels of $\mathrm{Mg}$ in CPtreated groups were not statistically different. CP-induced nephrotoxicity disturbs tubular reabsorption of $\mathrm{Mg}$, and depletion of $\mathrm{Mg}$ enhances nephrotoxicity [73-76]. The CPinduced hypomagnesemia is not related to the total dose of CP [77], and in animal model, hypomagnesemia develops from the third week after CP administration [78]. Furthermore, an increase in the serum $\mathrm{Mg}$ level after supplemental treatment is not expected [79], and the serum level of Mg did not change in ovariectomized rats treated with estradiol and vitamin E [71]. Accordingly, it seems that one week was not enough to observe $\mathrm{Mg}$ depletion by $\mathrm{CP}$ in our model.

\section{Conclusion}

In the presence of estradiol in the particular pharmacological dose used in the study, vitamins $\mathrm{C}$ and $\mathrm{E}$ or losartan could not be nephroprotectant against CP-induced nephrotoxicity. The exact mechanisms need to be defined, but it seems that coadministration of the agents with CP in ovariectomized rats promotes the oxidative stress and potency of $\mathrm{CP}$, which contribute to nephrotoxicity severity. This contribution abolishes protective effect of the vitamins and losartan.

\section{Acknowledgments}

This research was supported by Isfahan University of Medical Sciences (Grant no. 290223). The authors thank Dr. Alireza Rezaei for his assistance.

\section{References}

[1] J. A. Winston and R. Safirstein, "Reduced renal blood flow in early cisplatin-induced acute renal failure in the rat.," The American Journal of Physiology, vol. 249, no. 4, pp. F490-F496, 1985.

[2] G. Ramesh and W. Brian Reeves, "TNF- $\alpha$ mediates chemokine and cytokine expression and renal injury in cisplatin nephrotoxicity," Journal of Clinical Investigation, vol. 110, no. 6, pp. 835-842, 2002.

[3] C. A. Davis, H. S. Nick, and A. Agarwal, "Manganese superoxide dismutase attenuates cisplatin-induced renal injury: importance of superoxide," Journal of the American Society of Nephrology, vol. 12, no. 12, pp. 2683-2690, 2001.

[4] D. R. Luke, K. Vadiei, and G. Lopez-Berestein, "Role of vascular congestion in cisplatin-induced acute renal failure in the rat," Nephrology Dialysis Transplantation, vol. 7, no. 1, pp. 1-7, 1992.

[5] P. M. Deegan, C. Nolan, M. P. Ryan, M. A. Basinger, M. M. Jones, and K. R. Hande, "The role of the renin-angiotensin system in cisplatin nephrotoxicity," Renal Failure, vol. 17, no. 6, pp. 665-674, 1995. 
[6] S. Saleh, A. A. Ain-Shoka, E. El-Demerdash, and M. M. Khalef, "Protective effects of the angiotensin II receptor blocker losartan on cisplatin-induced kidney injury," Chemotherapy, vol. 55, no. 6, pp. 399-406, 2009.

[7] A. Naqshbandi, M. W. Khan, S. Rizwan, S. U. Rehman, and F. Khan, "Studies on the protective effect of dietary fish oil on cisplatin induced nephrotoxicity in rats," Food and Chemical Toxicology, vol. 50, no. 2, pp. 265-273, 2012.

[8] F. Ashrafi, M. Nematbakhsh, T. Safari et al., "A combination of vitamin $\mathrm{C}$ and losartan for cisplatin-induced nephrotoxicity in rats," Iranian Journal of Kidney Diseases, vol. 6, no. 5, pp. 361-365, 2012.

[9] J. M. Pérez-Rojas, C. E. Guerrero-Beltrán, C. Cruz, D. J. Sánchez-González, C. M. Martínez-Martínez, and J. PedrazaChaverri, "Preventive effect of tert-butylhydroquinone on cisplatin-induced nephrotoxicity in rats," Food and Chemical Toxicology, vol. 49, no. 10, pp. 2631-2637, 2011.

[10] P. D. Sanchez-Gonzalez, F. J. Lopez-Hernandez, F. PerezBarriocanal, A. I. Morales, and J. M. Lopez-Novoa, "Quercetin reduces cisplatin nephrotoxicity in rats without compromising its anti-tumour activity," Nephrology Dialysis Transplantation, vol. 26, no. 11, pp. 3484-3495, 2011.

[11] S. Atasayar, H. Gürer-Orhan, H. Orhan, B. Gürel, G. Girgin, and $\mathrm{H}$. Ozgunes, "Preventive effect of aminoguanidine compared to vitamin $\mathrm{E}$ and $\mathrm{C}$ on cisplatin-induced nephrotoxicity in rats," Experimental and Toxicologic Pathology, vol. 61, no. 1, pp. 23-32, 2009.

[12] E. S. M. El-Sayed, M. F. Abd-Ellah, and S. M. Attia, "Protective effect of captopril against cisplatin-induced nephrotoxicity in rats," Pakistan Journal of Pharmaceutical Sciences, vol. 21, no. 3, pp. 255-261, 2008.

[13] X. H. Liu, J. Li, Q. X. Li, Y. X. Ai, and L. Zhang, "Protective effects of ligustrazine on cisplatin-induced oxidative stress, apoptosis and nephrotoxicity in rats," Environmental Toxicology and Pharmacology, vol. 26, no. 1, pp. 49-55, 2008.

[14] Y. H. Kim, Y. W. Kim, Y. J. Oh et al., "Protective effect of the ethanol extract of the roots of Brassica rapa on cisplatininduced nephrotoxicity in LLC-PK1 cells and rats," Biological and Pharmaceutical Bulletin, vol. 29, no. 12, pp. 2436-2441, 2006.

[15] I. K. Mohan, M. Khan, J. C. Shobha et al., "Protection against cisplatin-induced nephrotoxicity by Spirulina in rats," Cancer Chemotherapy and Pharmacology, vol. 58, no. 6, pp. 802-808, 2006.

[16] Y. Shimeda, Y. Hirotani, Y. Akimoto et al., "Protective effects of capsaicin against cisplatin-induced nephrotoxicity in rats," Biological and Pharmaceutical Bulletin, vol. 28, no. 9, pp. 16351638, 2005.

[17] G. Karimi, M. Ramezani, and Z. Tahoonian, "Cisplatin nephrotoxicity and protection by milk thistle extract in rats," Evidence-based Complementary and Alternative Medicine, vol. 2, no. 3, pp. 383-386, 2005.

[18] A. Shirwaikar, S. Malini, and S. C. Kumari, "Protective effect of Pongamia pinnata flowers against cisplatin and gentamicin induced nephrotoxicity in rats," Indian Journal of Experimental Biology, vol. 41, no. 1, pp. 58-62, 2003.

[19] M. A. Mansour, A. M. Mostafa, M. N. Nagi, M. M. Khattab, and O. A. Al-Shabanah, "Protective effect of aminoguanidine against nephrotoxicity induced by cisplatin in normal rats," Comparative Biochemistry and Physiology C, vol. 132, no. 2, pp. 123-128, 2002.

[20] S. Y. Saad and A. C. Al-Rikabi, "Protection effects of taurine supplementation against cisplatin-induced nephrotoxicity in rats," Chemotherapy, vol. 48, no. 1, pp. 42-48, 2002.
[21] S. M. Somani, K. Husain, C. Whitworth, G. L. Trammell, M. Malafa, and L. P. Rybak, "Dose-dependent protection by lipoic acid against cisplatin-induced nephrotoxicity in rats: antioxidant defense system," Pharmacology and Toxicology, vol. 86, no. 5, pp. 234-241, 2000.

[22] L. M. Greggi Antunes, J. D'arc, and M. D. L. P. Bianchi, "Protective effects of vitamin C against cisplatin-induced nephrotoxicity and lipid peroxidation in adult rats: a dosedependent study," Pharmacological Research, vol. 41, no. 4, pp. 405-411, 2000.

[23] D. Appenroth, S. Fröb, L. Kersten, F. K. Splinter, and K. Winnefeld, "Protective effects of vitamin $\mathrm{E}$ and $\mathrm{C}$ on cisplatin nephrotoxicity in developing rats," Archives of Toxicology, vol. 71, no. 11, pp. 677-683, 1997.

[24] H. Bräunlich, D. Appenroth, and C. Fleck, "Protective effects of methimazole against cisplatin-induced nephrotoxicity in rats," Journal of Applied Toxicology, vol. 17, no. 1, pp. 41-45, 1997.

[25] J. Tokunaga, M. Kobayashi, A. Kitagawa, C. Nakamura, K. Arimori, and M. Nakano, "Protective effects of N-benzoyl amino acids on cisplatin nephrotoxicity in rats," Biological and Pharmaceutical Bulletin, vol. 19, no. 11, pp. 1451-1456, 1996.

[26] J. Tokunaga, M. Kobayashi, C. Nakamura, A. Kitagawa, K. Arimori, and M. Nakano, "Protective effect of N-benzoyl- $\beta$ alanine against cisplatin nephrotoxicity in rats," Renal Failure, vol. 18, no. 2, pp. 225-240, 1996.

[27] D. Appenroth, K. Winnefeld, H. Schroter, and M. Rost, "Beneficial effect of acetylcysteine on cisplatin nephrotoxicity in rats," Journal of Applied Toxicology, vol. 13, no. 3, pp. 189$192,1993$.

[28] T. Hayashi, Y. Watanabe, K. Kumano et al., "Protective effect of piperacillin against the nephrotoxicity of cisplatin in rats," Antimicrobial Agents and Chemotherapy, vol. 33, no. 4, pp. 513-518, 1989.

[29] K. Rjiba-Touati, I. A. Boussema, A. Belarbia, A. Achour, and H. Bacha, "Protective effect of recombinant human erythropoietin against cisplatin-induced oxidative stress and nephrotoxicity in rat kidney," International Journal of Toxicology, vol. 30, no. 5, pp. 510-517, 2011.

[30] K. Rjiba-Touati, I. Ayed-Boussema, C. Bouaziz et al., "Protective effect of erythropoietin against cisplatin-induced nephrotoxicity in rats: antigenotoxic and antiapoptotic effect," Drug and Chemical Toxicology, vol. 35, no. 1, pp. 89-95, 2012.

[31] K. W. Lee, J. Y. Jeong, B. J. Lim et al., "Sildenafil attenuates renal injury in an experimental model of rat cisplatin-induced nephrotoxicity," Toxicology, vol. 257, no. 3, pp. 137-143, 2009.

[32] B. Ulubaş, M. Y. B. Çimen, D. D. Apa, E. Saritaş, N. Muşlu, and Ö. B. Çimen, "The protective effects of acetylsalicylic acid on free radical production in cisplatin induced nephrotoxicity: an experimental rat model," Drug and Chemical Toxicology, vol. 26, no. 4, pp. 259-270, 2003.

[33] Y. Sadzuka, Y. Shimizu, Y. Takino, and S. Hirota, "Protection against cisplatin-induced nephrotoxicity in the rat by inducers and an inhibitor of glutathione S-transferase," Biochemical Pharmacology, vol. 48, no. 3, pp. 453-459, 1994.

[34] M. Nematbakhsh, F. Ashrafi, T. Safari et al., "Administration of vitamin $\mathrm{E}$ and losartan as prophylaxes in cisplatin-induced nephrotoxicity model in rats," Journal of Nephrology, vol. 25, no. 3, pp. 410-417, 2012.

[35] N. I. Weijl, T. J. Elsendoorn, E. G. W. M. Lentjes et al., "Supplementation with antioxidant micronutrients and chemotherapy-induced toxicity in cancer patients treated with cisplatin-based chemotherapy: a randomised, double-blind, 
placebo-controlled study," European Journal of Cancer, vol. 40, no. 11, pp. 1713-1723, 2004.

[36] A. A. Argyriou, E. Chroni, A. Koutras et al., "A randomized controlled trial evaluating the efficacy and safety of vitamin E supplementation for protection against cisplatin-induced peripheral neuropathy: final results," Supportive Care in Cancer, vol. 14, no. 11, pp. 1134-1140, 2006.

[37] A. Pace, D. Giannarelli, E. Galiè et al., "Vitamin e neuroprotection for cisplatin neuropathy: a randomized, placebocontrolled trial," Neurology, vol. 74, no. 9, pp. 762-766, 2010.

[38] A. R. R. Gonçalves, C. K. Fujihara, A. L. Mattar et al., "Renal expression of COX-2, ANG II, and AT1 receptor in remnant kidney: strong renoprotection by therapy with losartan and a nonsteroidal anti-inflammatory," American Journal of Physiology, vol. 286, no. 5, pp. F945-F954, 2004.

[39] N. D. Vaziri, Y. Bai, Z. Ni, Y. Quiroz, R. Pandian, and B. Rodriguez-Iturbe, "Intra-renal angiotensin II/AT1 receptor, oxidative stress, inflammation, and progressive injury in renal mass reduction," Journal of Pharmacology and Experimental Therapeutics, vol. 323, no. 1, pp. 85-93, 2007.

[40] J. Ullman, S. Eriksson, and M. Rundgren, "Losartan increases renal blood flow during isoflurane anesthesia in sheep," Acta Anaesthesiologica Scandinavica, vol. 45, no. 9, pp. 1168-1175, 2001.

[41] S. A. W. Dukacz and R. L. Kline, "Differing effects of enalapril and losartan on renal medullary blood flow and renal interstitial hydrostatic pressure in spontaneously hypertensive rats," Journal of Hypertension, vol. 17, no. 9, pp. 1345-1352, 1999.

[42] J. J. Cho, P. Cadet, E. Salamon, K. J. Mantione, and G. B. Stefano, "The nongenomic protective effects of estrogen on the male cardiovascular system: clinical and therapeutic implications in aging men," Medical Science Monitor, vol. 9, no. 3, pp. RA63-RA68, 2003.

[43] I. H. Chaudry and M. A. Choudhry, " $17 \beta$-estradiol: a novel hormone for improving immune and cardiovascular responses following trauma-hemorrhage," Journal of Leukocyte Biology, vol. 83, no. 3, pp. 518-522, 2008.

[44] R. K. Dubey and E. K. Jackson, "Cardiovascular protective effects of $17 \beta$-estradiol metabolites," Journal of Applied Physiology, vol. 91, no. 4, pp. 1868-1883, 2001.

[45] M. E. Mendelsohn, "Protective effects of estrogen on the cardiovascular system," American Journal of Cardiology, vol. 89, no. 12, supplement 1, pp. 12E-18E, 2002.

[46] M. E. Mendelsohn and R. H. Karas, "The protective effects of estrogen on the cardiovascular system," New England Journal of Medicine, vol. 340, no. 23, pp. 1801-1811, 1999.

[47] M. Nematbakhsh, M. Ghadesi, M. Hosseinbalam et al., "Oestrogen promotes coronary angiogenesis even under normoxic conditions," Basic and Clinical Pharmacology and Toxicology, vol. 103, no. 3, pp. 273-277, 2008.

[48] D. H. Kang, E. S. Yu, K. I. Yoon, and R. Johnson, "The impact of gender on progression of renal disease: potential role of estrogen-mediated vascular endothelial growth factor regulation and vascular protection," American Journal of Pathology, vol. 164, no. 2, pp. 679-688, 2004.

[49] S. R. Silbiger and J. Neugarten, "The role of gender in the progression of renal disease," Advances in Renal Replacement Therapy, vol. 10, no. 1, pp. 3-14, 2003.

[50] Q. He, C. H. Liang, and S. J. Lippard, "Steroid hormones induce HMG1 overexpression and sensitize breast cancer cells to cisplatin and carboplatin," Proceedings of the National Academy of Sciences of the United States of America, vol. 97, no. 11, pp. 5768-5772, 2000.
[51] M. A. Beleh, Y. C. Lin, and R. W. Brueggemeier, "Estrogen metabolism in microsomal, cell, and tissue preparations of kidney and liver from Syrian hamsters," Journal of Steroid Biochemistry and Molecular Biology, vol. 52, no. 5, pp. 479489, 1995.

[52] M. Nematbakhsh, A. Talebi, H. Nasri et al., "Some evidence for sex-based differences in cisplatininduced nephrotoxicity in rats," Clinical and Experimental Medical Letters, vol. 53, no. 12, pp. 29-32, 2012.

[53] M. Haghighi, M. Nematbakhsh, A. Talebi et al., "The role of angiotensin II receptor 1 (AT1) blockade in cisplatin-induced nephrotoxicity in rats: gender-related differences," Renal Failure, vol. 34, no. 8, pp. 1046-1051, 2012.

[54] J. Y. Song, M. J. Kim, H. H. Jo et al., "Antioxidant effect of estrogen on bovine aortic endothelial cells," Journal of Steroid Biochemistry and Molecular Biology, vol. 117, no. 1-3, pp. 7480, 2009.

[55] V. Mann, C. Huber, G. Kogianni, F. Collins, and B. Noble, "The antioxidant effect of estrogen and Selective Estrogen Receptor Modulators in the inhibition of osteocyte apoptosis in vitro," Bone, vol. 40, no. 3, pp. 674-684, 2007.

[56] E. Speir, Z. X. Yu, K. Takeda, V. J. Ferrans, and R. O. Cannon, "Antioxidant effect of estrogen on cytomegalovirus-induced gene expression in coronary artery smooth muscle cells," Circulation, vol. 102, no. 24, pp. 2990-2996, 2000.

[57] S. Y. Saad, T. A. O. Najjar, M. H. Daba, and A. C. Al-Rikabi, "Inhibition of nitric oxide synthase aggravates cisplatininduced nephrotoxicity: effect of 2-amino-4-methylpyridine," Chemotherapy, vol. 48, no. 6, pp. 309-315, 2002.

[58] C. A. Hamilton, S. Groves, H. V. O. Carswell, M. J. Brosnan, D. Graham, and A. F. Dominiczak, "Estrogen treatment enhances nitric oxide bioavailability in normotensive but not hypertensive rats," American Journal of Hypertension, vol. 19, no. 8, pp. 859-866, 2006.

[59] E. L. Leung, M. Fraser, R. R. Fiscus, and B. K. Tsang, "Cisplatin alters nitric oxide synthase levels in human ovarian cancer cells: involvement in p53 regulation and cisplatin resistance," British Journal of Cancer, vol. 98, no. 11, pp. 1803-1809, 2008.

[60] M. Nematbakhsh and M. Khazaei, "The effect of estrogen on serum nitric oxide concentrations in normotensive and DOCA Salt hypertensive ovariectomized rats," Clinica Chimica Acta, vol. 344, no. 1-2, pp. 53-57, 2004.

[61] S. Soylemez, H. Gurdal, A. Sepici, and F. Akar, "The effect of long-term resveratrol treatment on relaxation to estrogen in aortae from male and female rats: role of nitric oxide and superoxide," Vascular Pharmacology, vol. 49, no. 2-3, pp. 97105, 2008.

[62] D. A. Wink, J. A. Cook, D. Christodoulou et al., "Nitric oxide and some nitric oxide donor compounds enhance the cytotoxicity of cisplatin," Nitric Oxide, vol. 1, no. 1, pp. 88-94, 1997.

[63] D. B. Baxi, P. K. Singh, K. D. Vachhrajani, and A. V. Ramachandran, "Melatonin supplementation in rat ameliorates ovariectomy-induced oxidative stress," Climacteric. In press.

[64] R. C. Srivastava, A. Farookh, N. Ahmad, M. Misra, S. K. Hasan, and M. M. Husain, "Evidence for the involvement of nitric oxide in cisplatin-induced toxicity in rats," BioMetals, vol. 9, no. 2, pp. 139-142, 1996.

[65] K. I. Watanabe, A. Hess, W. Bloch, and O. Michel, "Expression of inducible nitric oxide synthase (iNOS/NOS II) in the vestibule of guinea pigs after the application of cisplatin," AntiCancer Drugs, vol. 11, no. 1, pp. 29-32, 2000.

[66] K. I. Watanabe, A. Hess, O. Michel, and T. Yagi, "Nitric oxide synthase inhibitor reduces the apoptotic change in the 
cisplatin-treated cochlea of guinea pigs," Anti-Cancer Drugs, vol. 11, no. 9, pp. 731-735, 2000.

[67] N. A. G. Santos, C. S. Catão, N. M. Martins, C. Curti, M. L. P. Bianchi, and A. C. Santos, "Cisplatin-induced nephrotoxicity is associated with oxidative stress, redox state unbalance, impairment of energetic metabolism and apoptosis in rat kidney mitochondria," Archives of Toxicology, vol. 81, no. 7, pp. 495-504, 2007.

[68] T. A. Ajith, S. Usha, and V. Nivitha, "Ascorbic acid and $\alpha$ tocopherol protect anticancer drug cisplatin induced nephrotoxicity in mice: a comparative study," Clinica Chimica Acta, vol. 375, no. 1-2, pp. 82-86, 2007.

[69] M. Ulas and M. Cay, “17 $\beta$-Estradiol and vitamin E modulates oxidative stress-induced kidney toxicity in diabetic ovariectomized rat," Biological Trace Element Research, vol. 144, no. 1-3, pp. 821-831, 2011.

[70] K. Moorthy, D. Sharma, S. F. Basir, and N. Z. Baquer, "Administration of estradiol and progesterone modulate the activities of antioxidant enzyme and aminotransferases in naturally menopausal rats," Experimental Gerontology, vol. 40, no. 4, pp. 295-302, 2005.

[71] M. Ulas and M. Cay, "Effects of $17 \beta$-estradiol and vitamin $\mathrm{E}$ treatments on blood trace element and antioxidant enzyme levels in ovariectomized rats," Biological Trace Element Research, vol. 139, no. 3, pp. 347-355, 2011.

[72] D. M. Maliakel, T. V. Kagiya, and C. K. K. Nair, "Prevention of cisplatin-induced nephrotoxicity by glucosides of ascorbic acid and $\alpha$-tocopherol," Experimental and Toxicologic Pathology, vol. 60, no. 6, pp. 521-527, 2008.

[73] M. P. Goren, "Cisplatin nephrotoxicity affects magnesium and calcium metabolism," Medical and Pediatric Oncology, vol. 41, no. 3, pp. 186-189, 2003.

[74] E. Hodgkinson, H. L. Neville-Webbe, and R. E. Coleman, "Magnesium depletion in patients receiving cisplatin-based chemotherapy," Clinical Oncology, vol. 18, no. 9, pp. 710-718, 2006.

[75] H. Lajer, M. Kristensen, H. H. Hansen, S. Christensen, T. Jonassen, and G. Daugaard, "Magnesium and potassium homeostasis during cisplatin treatment," Cancer Chemotherapy and Pharmacology, vol. 55, no. 3, pp. 231-236, 2005.

[76] H. Lajer, M. Kristensen, H. H. Hansen et al., "Magnesium depletion enhances cisplatin-induced nephrotoxicity," Cancer Chemotherapy and Pharmacology, vol. 56, no. 5, pp. 535-542, 2005.

[77] G. Ariceta, J. Rodriguez-Soriano, A. Vallo, and A. Navajas, "Acute and chronic effects of cisplatin therapy on renal magnesium homeostasis," Medical and Pediatric Oncology, vol. 28, no. 1, pp. 35-40, 1997.

[78] V. Mavichak, N. L. M. Wong, and G. A. Quamme, "Studies on the pathogenesis of cisplatin-induced hypomagnesemia in rats," Kidney International, vol. 28, no. 6, pp. 914-921, 1985.

[79] V. Virág, Z. May, I. Kocsis, A. Blázovics, and K. Szentmihályi, "Effects of magnesium supplementation on the calcium and magnesium levels, redox homeostasis in normolipidemic and alimentary induced hyperlipidemic rats," Orvosi Hetilap, vol. 152, no. 27, pp. 1075-1081, 2011. 


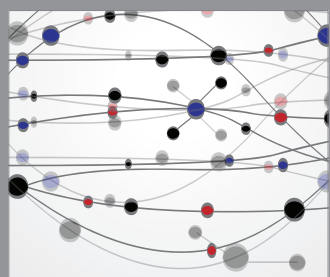

The Scientific World Journal
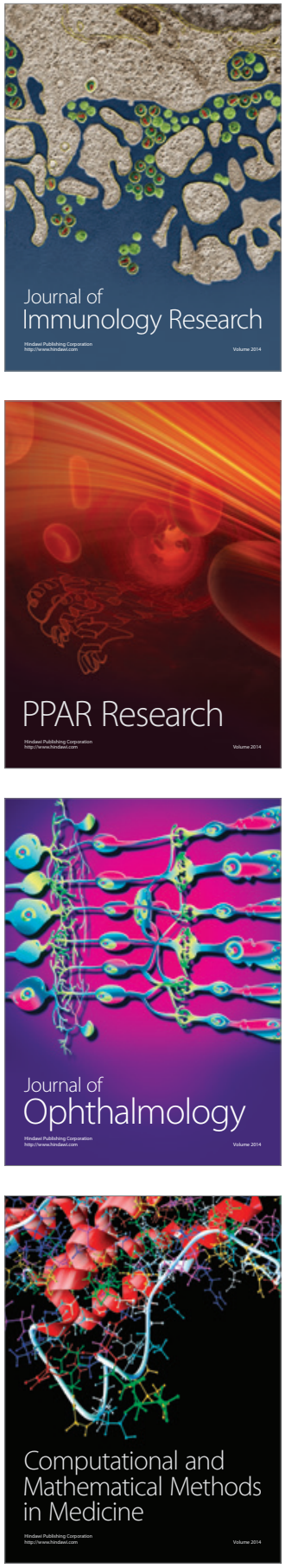

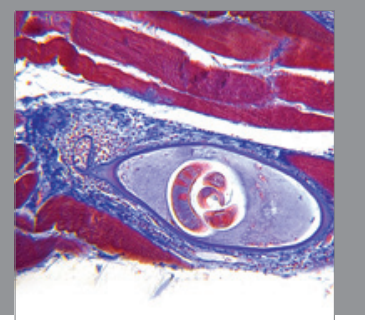

Gastroenterology

Research and Practice
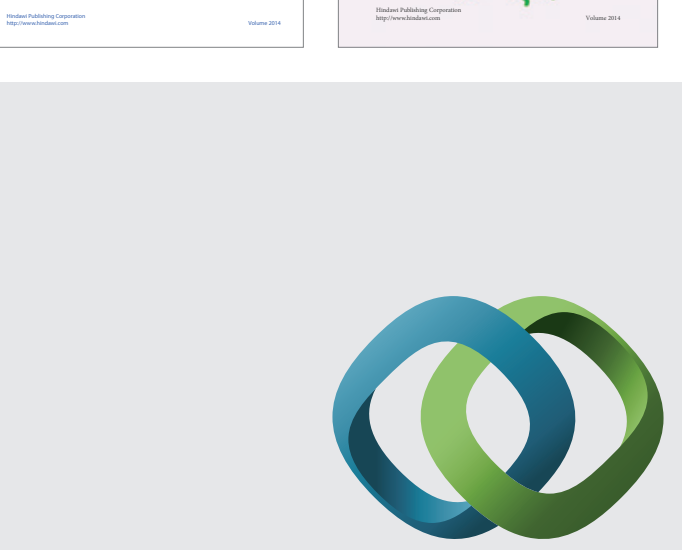

\section{Hindawi}

Submit your manuscripts at

http://www.hindawi.com
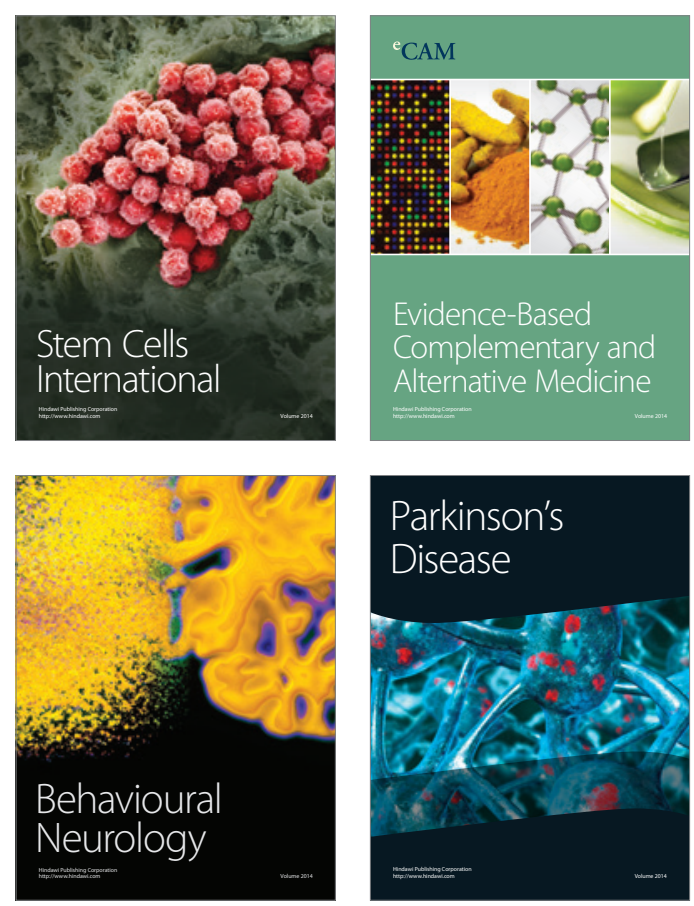

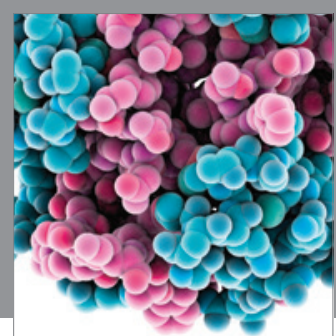

Journal of
Diabetes Research

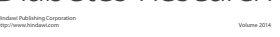

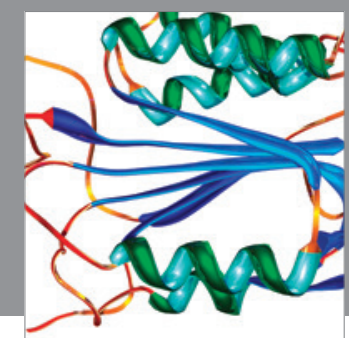

Disease Markers
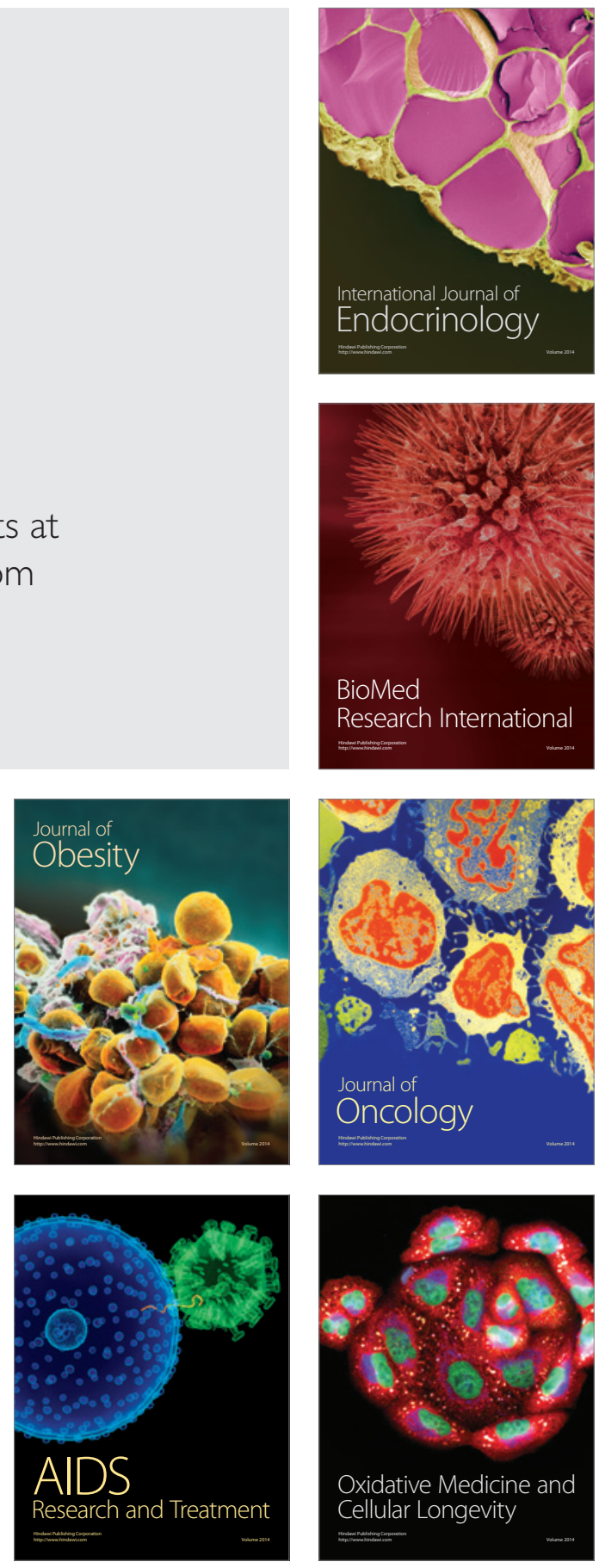